\title{
Prevention activities in ship loading and unloading operations
}

\author{
Daniel Nicu Fraitag*, Mihai Popescu-Stelea, Roland Iosif Moraru, and Gabriel Bujor Băbuţ \\ University of Petrosani, Faculty of Mines, Department of Management and Industrial Engineering, 20 \\ University Street, 332006 Petrosani, Romania
}

\begin{abstract}
Only an objective knowledge of safety and health at work reality on the harbor platform and an active participation of all stakeholders (employers, unions, workers) can bring an improvement in this activity. The prevention of accidents at work by ensuring safe and healthy working conditions and maintaining the Occupational Safety and Health Management system are factors that continuously develop and improve safety performance by helping to actively manage risks. This paper aims to systematize the information available, both at European and national level so as to develop a strategy at the organizational level that can be included in a guide to optimal safety and health practices for harbor operations. The paper also proposes relevant practical aspects of safety and health at work in the activities carried out in the loading and unloading flow in / from the port of the ship, trying to support the knowledge and understanding of identification, assessment and prevention of specific risks.
\end{abstract}

\section{Introduction}

The fundamental purpose of transport and maritime trade is to ensure a safe flow of goods both nationally and internationally. This system is composed of three basic elements represented by: ship - the means of transport of goods; goods; carriers and ports, terminal points where goods are trans-shipped and stored. Many of the methods of handling goods have been improved by modifying them and bringing the safety of port workers higher. However, the emergence of new risks in the handling of goods in ports shows that this job remains a risky one. An important factor is the constant development of risk identification and management systems as well as the tendency to invest in know-how, including for the benefit of port workers.

The nature of the activities carried out in the harbor, the large volume of work and the fast pace in which they work, sometimes lead to serious accidents for both people and material losses, sometimes affecting the environment. Through an efficient safety management, the legal requirements for the prevention of accidents can be implemented within the organization, and in case of their occurrence, the minimization of the impact through the undertaking of actions. A permanent factor is the application of policies,

\footnotetext{
${ }^{*}$ Corresponding author: ndanfreitag@yahoo.com
} 
procedures and practices, aiming at identifying, analyzing and treating, subsequently monitoring the risks in order to reduce them.

Occupational safety and health is an area where techniques are constantly evolving [1 3]. The requirements risk being left behind, no longer presenting the reality and in this case the detailed guidelines may take the form of codes of practice and technical principles of a technical nature $[5,6]$. In the harbor it was felt the need to complete the legislation on safety and health at work and then they resorted to the elaboration of these codes [4]. These codes are present in all major European harbors, but also on other continents. The codes are approved by the ILO and comply with the conventions [7].

These aim to provide practical guidance, based on a risk management framework to help employers, employees and those with occupational safety and health responsibilities. It includes regulations for the identification, assessment and control of risks specific to harbor operations.

\section{Steps taken for safe resource allocation in harbor loading- unloading operations}

The most important role in the harbor community is played by harbor operators [8]. Their main objectives are to maximize profits and market development, objectives that are also pursued by shipowners. Often their goals leave the activity of safety and health at work in the background, with a low priority [9]. In order to achieve the objectives, it is necessary that the management of the planning of harbor operations activities be cursive, realistic and done in the smallest detail [10].

Within the activities carried out in the arrival / departure flow of the ship in and out of the harbor, two important responsibilities are distinguished:

i. Liability of seafarers (on board the ship), responsible for the operations carried out until the ship docked at the quay and its departure from the place of operation:

- The ship's crew has the task of ensuring the ship's departure at the entrance to the harbor with the support of the local pilot and the towing vessel that help the mooring maneuver. The crew and the longshoremen tie the ship to the quay and secure it;

- After completing the mooring maneuver, descend the access ladder on the quay. Throughout the stay, they will make sure that it is adjusted to the quay according to the change in the draft of ships that vary when unloading or loading. The ladder will have a safety net;

- The store covers of the ship will be operated by the crew; if it is necessary to use the loading-unloading equipment on board the ship, it will be put into operation by the crew on board.

- The master of the vessel shall make available the plan of operations and shall supervise the unloading/loading activity together with the operator so as not to jeopardize the stability of the vessel.

- All these operations that are performed by the crew on board the ship are found in the role (duties specified in international conventions) of each member of the crew according to the position he holds.

ii. The responsibility of the harbor operator, the personnel on the quay, from the mooring of the ship to its untying from the quay (figure 1). All operations carried out during the unloading-loading of the ship shall be carried out by the harbor operator in consultation with the master of the ship. 


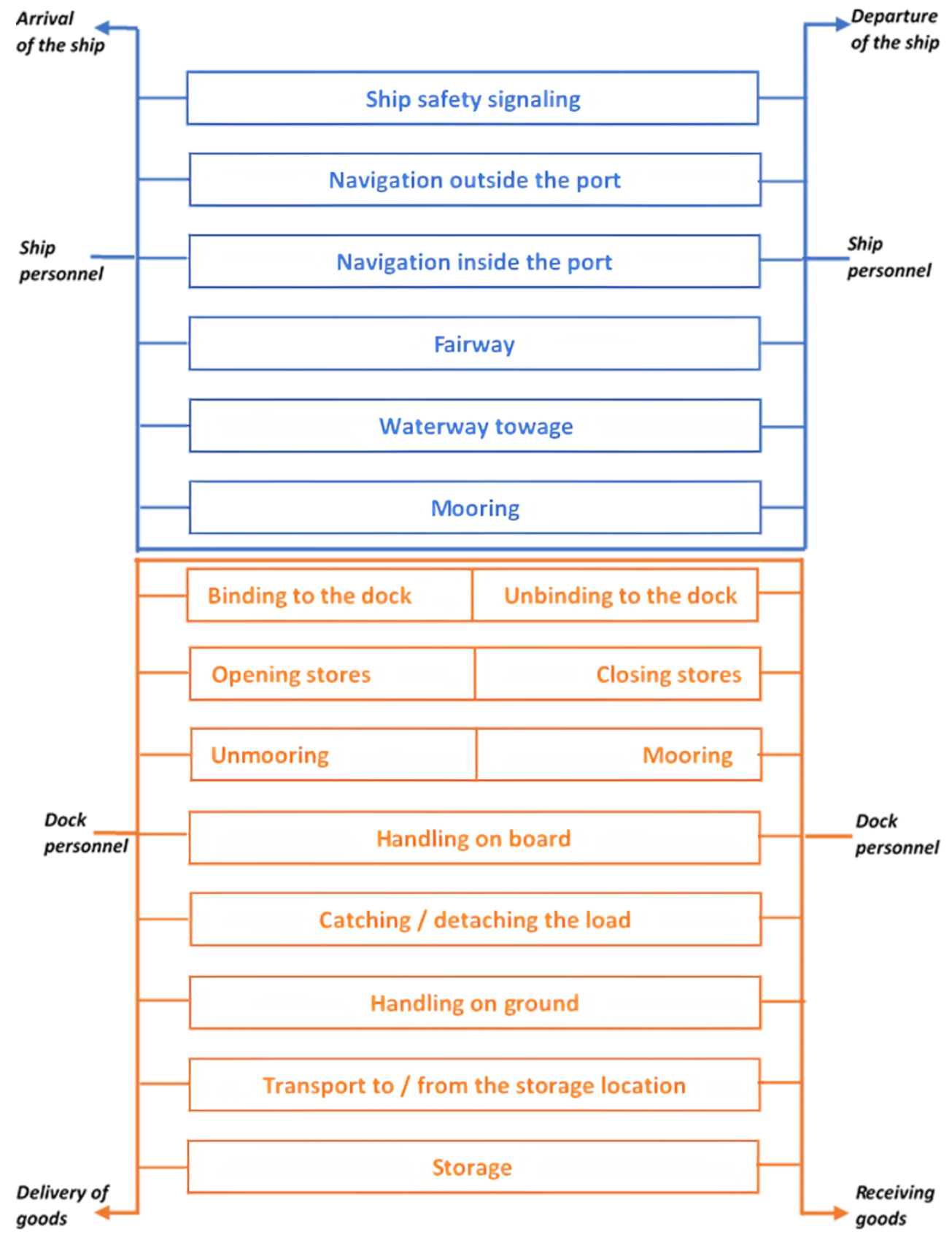

Fig. 1. The arrival / departure flow-sheet of the ship in and out of the harbour [11]

The legislation regulating occupational safety and health on board ships is extensive and uniform, being updated whenever the need is felt. This legislation is based on four pillars [12]:

- Maritime Labor Convention. MLC Convention;

- SOLAS which is the IMO convention for the protection of human life at sea; 
- International Convention on Standards of Training, Certification and Surveillance for STCW Navigators;

- MARPOL.

For the harbor activity, a complex activity that includes along with the handling of goods, their unloading and mooring, transport to and from the place of storage, storage, there is a national legislation that transposes the European Directives. This legislation proves to have shortcomings and does not strictly concern the harbor area.

Strictly addressing the flow of loading and unloading operations it can be said that the assessment of the risks identified at all stages of the flow, the development of appropriate measures helps to raise awareness of the dangers associated with the transfer of cargo between ship and quay and all related activities. , encouraging the consistent application of safe harbor practices, addressing occupational safety and health issues of berths and regulatory requirements. It also provides a basis on which safety training programs can be developed and implemented; helps strengthen the safety culture in the harbor sector.

Preparation for loading and unloading operations shall begin before the ship enters harbor. Figure 2 shows the steps to be taken in order to operate the ship. Depending on the type of ship and cargo, the operating berth is prepared.

a. The lighting, the access ways and the platform of the berth are checked;

- GD 1091/2006 - on the minimum safety and health requirements for the workplace.

- GD 971/2006 - on the minimum requirements for signs of safety and / or health at work.

b. The class of goods, the quantity and the type of packaging of the goods to be operated shall be determined;

- GD 1093/2006 - on establishing the minimum safety and health requirements for the protection of workers against the risks related to exposure to carcinogens or mutagens at work.

- GD 1092/2006 - on the protection of workers against the risks related to exposure to biological agents at work.

- GD 1218/2006 - on establishing the minimum safety and health requirements for the protection of workers against the risks related to the presence of chemical agents.

- GD 1058/2006 - on the minimum requirements for improving the safety and health protection of workers who may be exposed to a potential risk due to explosive atmospheres.

c. The approach of the operating method is established;

Law 319/2006 - on training

- GD 1146 - on minimum safety and health requirements for the use of work equipment by workers

- GD 1048/2006 - on the minimum safety and health requirements for the use of personal protective equipment by workers at work.

- GD $1051 / 2006$ - on the minimum safety and health requirements for manual handling of masses.

d. The handling of goods is determined;

- Technical verification and ISCIR (State Inspection for Control of Boilers, Pressure Vessels and Hoisting)inspections of the equipment to be used.

- GD 971/2006 - on the minimum requirements for safety and / or health signs at work. 


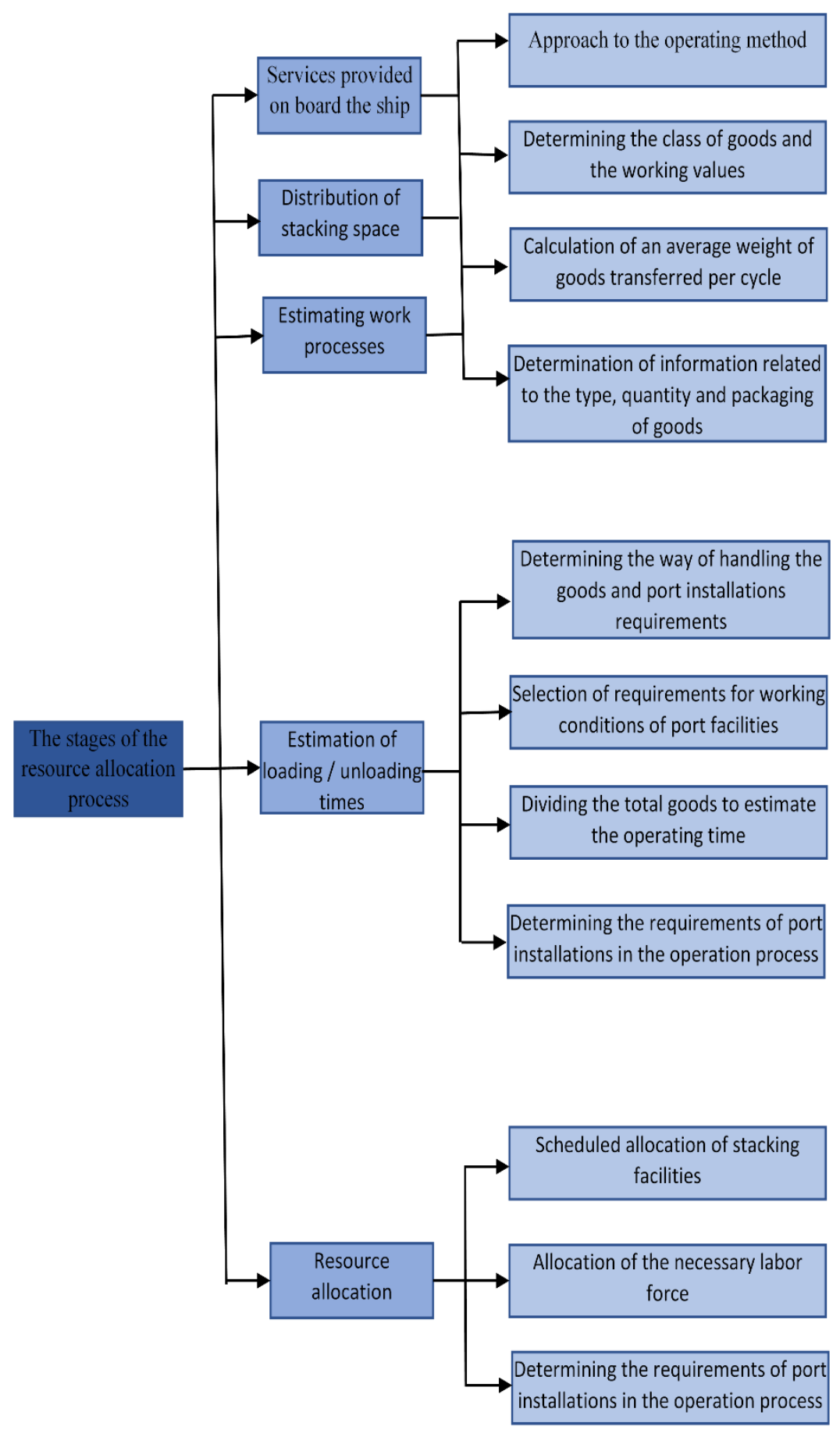

Fig. 2. Stages of the process of allocating resources in the operation of the ship 
e. Execution of dunnage;

- GD 1146 - on the minimum safety and health requirements for the use of work equipment by workers.

- GD $1051 / 2006$ - on the minimum safety and health requirements for manual handling of masses.

f. Execution of mooring of goods;

- GD 1146 - on the minimum safety and health requirements for the use of work equipment by workers.

- GD $1051 / 2006$ - on the minimum safety and health requirements for manual handling of masses.

g. Raising the level of manifestation of the employer in the management of OSH is reflected in the application of the legislation on health monitoring and employment of employees, at the level of the entity:

- GD 600/2007 on the protection of young people at work.

- GD 557/2007 on the completion of measures to promote improvement

- occupational safety and health for employees employed under a fixed-term individual employment contract and for temporary employees employed by temporary staff.

- Law 355/2007 on the supervision of workers' health.

- Law 346/2002 on insurance for work accidents and occupational diseases.

The shipping industry is not a stranger to standards. Statutory regulations, classification society rules, international agreements and national specifications are part of the variety of Rules and regulations the industry has to follow. Systems for assuring that a ship is following all mandatory regulation are developed by classification companies in co-operation with each specific shipping company.

\section{Common specific risks in the activity of loading-unloading ships}

In the activity of loading and unloading ships are engaged workers with distinct trades who work in complex teams coordinated by a section chief. The activity on the quay in the operations carried out on a ship is coordinated by the berth operator. It organizes and tracks the route of the goods from the ship to the place of storage (warehouse - ship) or their shipment to the final destination by loading in the means of transport (car or railroad). $\mathrm{He}$ subordinates the team performing the loading / unloading operations, consisting in:

- mechanized dock truck (wharf crane, wheeled crane, forklift truck, special equipment operator);

- tractor dock;

- loading dock that performs the transfer of cargo quay - ship - quay and its stacking;

- mooring dock that executes the dunnage (fardage) and mooring of the goods;

- warehouse cleaner;

- $\quad$ ship binder.

Observing the specific environment of the workplace, determining work tasks, operating modes, analyzing external factors of influence (marine environment, meteorological factors), analysis of psychological, social and physical factors that are likely to contribute to stress and their interaction with organizational and environmental factors, there can be a projection of the risks that are largely common or influences directly or indirectly the risks of each trade. The following were identified as common risks:

- Pneumoconiogenic dust (especially when handling bulk powder materials); 
- Overturning parts, materials, uninsured against uncontrolled movements;

- Fastening, gearing, hitting by forklifts, tractors, trailers, etc. in the work area;

- Rolling of parts, materials with rotation surfaces (pipes, shafts, drums, etc.);

- Stack collapse at loss of stability - accidents, accidental hanging, etc;

- $\quad$ Free fall of tools, parts, materials, loads transported by crane, etc. from height;

- Deviation from the normal trajectory of the loads in case of incorrect operation of the control systems or in balance;

- Hit by ropes, cables, gaskets, mesh, etc. as a result of shocks or their rupture in load (overload, improper condition, etc.);

- $\quad$ Direct touch of electric shock: stripped cables, unsecured switchboards;

- Toxic gases, vapors, aerosols, in particular from products stored in warehouses, gas warehouses, ships or forklift and tractor engines;

- Working in the marine environment - premature wear of the body;

- Dynamic effort to manually manipulate the masses vicious positions, osteoarticular disorders;

- Adoption of non-ergonomic methods for manual handling of masses;

- Non-compliance with working procedures for handling, tying and securing goods;

- Climbing on stacks in case of non-existence or blocking of access roads;

- Travel, parking in dangerous areas - under the load of lifting equipment, on roads and railways, on the edge of berths or cargo warehouses, scaffolding, ships, etc .;

- Falling from height by imbalance, slipping (in warehouses, on the ladder, on the platforms of means of roads and railways transport);

- Accidental communications;

- Failure to use PPE and other means of protection.

Ports and docks can be hazardous workplaces. Some hazards are unique to docks and ships, while others are common in many workplaces, but manifest themselves in unique ways in the docks environment. While every port is itself unique in terms of its physical configuration and range of activities, all work in ports and docks can be carried out safely provided the appropriate risk assessments have been carried out and the necessary control measures are communicated to those concerned, and implemented by them.

\section{Conclusions}

The harbor industry is a complex system with a relatively large number of specific risks due, in particular, to the diversity of ship types and cargo operated. The multitude of operating methods, the diversity of specific equipment used, which largely varies from one type of ship to another creates difficulties in Occupational Health and Safety management. The preparation of operations on the ship must comply with a specific flow that includes: information, specific analysis, exact calculations and technical and organizational principles, which were summarized in the paper.

The operations being distinct, each of them having its own particularity, leads to the elaboration of own instructions that have as priority the detailing of the activities. Unqualified personnel are used in the execution of complex operations that exceed their knowledge and experience. There is a need for continuous improvement of harbor workers, their specialization in order to learn new work systems; the part of the courses should not be reduced to the State Inspection for Control of Boilers, Pressure Vessels and Hoisting authorization courses that take place over a long period of time.

A significant improvement can be brought by the professional trainings (monthly, quarterly) within the entity together with the regular occupational safety and health training at work. Another important factor is the choice of work equipment used in this activity. Other 
improvement measures are related to: i) Determination of fardage materials and choice of mooring devices compatible with the goods and the type of vessel; ii) Careful and permanent monitoring of working conditions in relation to the health of workers and especially of occupational diseases, in order to recommend prophylactic measures; iii) Improving the national legislative framework in the field of harbor workers protection by addressing the specifics of the field; iv) elaboration by experts of a good practices guide for Romanian harbor following consultations with all stakeholders.

Risk assessment for ships should be continual, flexible, reviewed regularly to improve safety and preventing pollution. Since 'risk' is never a constant or concrete entity, the divergence of the nature of perception and anticipation the level of danger from the risk undertaken is resolved by experience, training and disposition. Human behavior towards issues, general awareness, and constant vigilance of those involved, all play a vital role in the organisation's decision-making process in the risk assessment in ship operations.

Improving interpersonal support and social norm also can be an effort to improve compliance with PPE in workplaces. Good PPE implementation can decrease the risk of occupational injury and disease and also decrease the cost of occupational injury and disease. PPE used by workers should be based on workers' need and risk in workplaces. Where a number of berth and terminal operators exist within the one port, they are required to work together, in cooperation with the port authority, to ensure effective safety management systems, which may include, for example, security and environmental management considerations across the entire port. Operators and employers using common user facilities and shared areas, including roads within a port, have a duty to co-operate with each other in ensuring a safe workplace for all concerned. There should be documented protocols, rules and procedures in relation to the safe operation and management of these facilities and areas. The operators of leased or privately owned facilities within a port are normally responsible for their safe management and operation, including the loading and unloading of ships at berths under their control. They have a duty to ensure that all plant, equipment or infrastructure that they control is maintained in a safe condition and to notify others likely to be affected by their activities of relevant safety and health information.

\section{References}

1. G.B. Băbuţ, R.I. Moraru, Proceedings of the 16th International Multidisciplinary Scientific GeoConference SGEM 2016 2, 635-642 (2016)

2. R.I. Moraru, G.B. Băbuţ, M. Popescu-Stelea, Quality - Access to Success 15(139), 104-108 (2014)

3. Popescu-Stelea, M., Moraru, R.I., Băbuț, G.B., Lupu-Dima, L., An exporatory study on workplace accidents and illnesses cost analysis tools, MSE 2019 Sibiu, Romania (2019)

4. M. Majid, G. Iran, O. Behrooz, Risk assessment in the maritime industry, Engeneering technology and applied science research, vol 7, no.1, (2017)

5. R.I. Moraru, G.B. Băbuţ, Quality - Access to Success 11(4), pp. 50-59 (2010)

6. R.I. Moraru, G.B. Băbuţ, M. Popescu-Stelea, Quality - Access to Success 15(139), 104-108 (2014)

7. Nicolae F1., Sisteme navale si portuare de operare. Terminale portuare speciaizate, vol. II, editura Academiei Navale, 2012.

8. Berg H.P., Human factors and safety culture in maritime safety, International journals on maritime navigation and safety on sea transportation, vol. 7, no.3, (2013).

9. Olle. B, Tore. J. L, Risk control in the shipping industry, relevant applications for the preventions of accidents, Safety science monitor, vol 4, (2000).

10. Meltin C. Seculek. C, Analitical HFACS for investigating human errors in shipping accidents, Accident analysis and prevention, 41, (2009)

11. International Maritime Organization, MARPOL 73/78 IMO, London, 1992

12. International Labour Office. Safety and health in ports ILO code of practice, ISBN 92-2- $115287-$ 1, Geneva, 2005 